phẫu thuật ung thư tuyến giáp tại Bệnh viện Đại học y Hà Nội, Luận văn thạc sĩ y học, Đại học y Hà Nội.

5. Mai Thế Vương (2019), Nhấn xét đặc điểm lâm sàng, cận lâm sàng và kết quả phẩu thuật của bệnh nhân vi ung thư tuyến giáp thể nhú tại bệnh viện K,Luận văn thạc sĩ y học, Đại học y Hà Nội.

6. Bray F, Ferlay J, Soerjomataram I, et al (2018). "Global cancer statistics 2018: GLOBOCAN estimates of incidence and mortality worldwide for
36 cancers in 185 countries". 68 (6), 394-424.

7. Katoh $H$, Yamashita $K$, Enomoto $T$, et al (2015). "Classification and general considerations of thyroid cancer". 3 (1), 1045.

8. Krajewska j, Kukulska A, OczkoWojciechowska M, et al (2020). "Early Diagnosis of Low-Risk Papillary Thyroid Cancer Results Rather in Overtreatment Than a Better Survival". Front Endocrinol (Lausanne), 11571421.

\title{
KẾT QUẢ PHỤC HỒI CHỨC NĂNG SỚM VỚI RỐI LOẠN NUỐT Ở NGƯỜI BỆNH NHỒI MÁU NÃO CẤP ĐIỀU TRI TẠI KHOA THẦN KINH BÊ̂NH VIỆN BACH MAI
}

\author{
Nguyễn Mạnh Huynh*, Võ Hồng Khôi*, \\ Hoàng Thị Xuân Hương**, Nguyễn Ngọc Hòa***
}

\section{TÓM TẮT}

Đă̆t vấn đề: Đôt quy não là một bênh rất nghiêm trọng và thường để lại hậ̣u quả nặng nề cho bản thân người bênh, gia đình và toàn xã hội nếu không được chăm sóc và điều trị kịp thời. Đây là vấn đề thời sự của tất cả các quốc gia trên toàn thế giới, trong đó có Việt Nam. Rối loạn nuốt sau đột quy xảy ra ở 23-65\% nqười bênh, trong số này, có $37 \%$ phát triển thành viêm phổi hít và gây ra những hậu quả nghiêm trọng. Ngày nay, với sư tiến bô của y hợ, Phục hồi chức năng giai đoạn cấp góp phần phục hồi tiên lượng cho người bệnh Trong đột quy não thì liêt và rối loạn nuốt là dấu hiệu thường gặp và hay đi kèm với nhau. Nếu không được vận động sớm người bệnh dễ mắc teo cơ, cứng khớp, sặc, viêm phổi và suy dinh dưỡng. Xuất phát từ vấn đ̛̣̂̀ trên chúng tôi tiến hành nghiên cứu này. Mục Tiêu: Đánh giá kết quả phục hồi chức năng sớm với rối loạn nuốt ở người bệnh nhî̀i máu não cấp điều trị tại Khoa Thần Kinh Bệnh Viện Bạch Mai. Đối tượng và phương pháp nghiên cửu: P̉ương pháp giả thực nghiẹm không có nhóm chứng (quasiexperiment) trền 96 người bệnh đột quy não cấp (theo tiêu chuẩn chẩn đoán của WHO) có rối loạn nuốt được điều trị tại TT Thần Kinh BV Bạch Mai từ tháng 1 đến tháng 6 năm 2021. Thang điểm GUSS (The Gugging Swallowing Screen) được dùng để đánh giá rối loạn nuốt cho người bệnh. Kết quả và bàn luận: Phần lớn người bê̂nh ở độ tuổi tử 61-70 tuổi (33 người, chiếm $34,4 \%$ ). Sau khi được can thiệp phục hồi chức năng nuốt tất cả 96 người bệnh đều có sự cải thiên về khả năng nuốt tốt hơn so với trước can thiệp (Điểm GUSS tăng từ $11,09 \pm 3,37$ lên $14.31 \pm 1,87$, p $<0,0001)$. Kết luận: Tiến hành áp dụng các bài tập nuốt trên người bệnh đột quỵ não cấp có rối loạn nuốt

*Bênh viện Bạch Mai

**Trường Đai hoc Phenikaa

***Bệnh viện Hữu nghị Đa khoa Nghệ An.

Chịu trách nhiệm chính: Nguyễn Mạnh Huynh

Email: Huynhtkbm@gmail.com

Ngày nhận bài: 16.6.2021

Ngày phản biên khoa hoc: 13.8.2021

Ngày duyệt bài: 13.8.2021 sớm bước đầu đem lại kết quả tốt trong phục hồi khả năng nuốt cho người bệnh.

Tư khóa: Đột quy., tăng huyết áp, rối loạn nuốt, bài tập nuốt.

\section{SUMMARY \\ EVALUATE INITIIAL EFFECTIVENESS OF SWALLOWING REHABILITATION FOR \\ PATIENTS WITH POST-ACUTE STROKE DYSPHAGIA IN NEUROLOGY CENTER OF BACHMAI HOSPITAL}

Background: Stroke is a life-threatening illness. If left without prompt medical treament, stroke resulted in long-term complications for the patient and increasing economic burden. This health condition is the current global issues and Vietnam is not exceptional. Swallowing disorder occurs in $23-65 \%$ of post-stroke patients. Among those, dysphagia lead to aspiration pneumonia in $37 \%$ following severe consequences.Nowadays, due largely to medical advances, rehabilitation in acute stroke patients contribute to the good outcome. In stroke patients, swallowing disorder is common sign and often accompanied by paralysis. Patient who do not receive early physical therapy is prone to develop muscle atrophy, spasticity, aspiration, pneumonia and malnutrition. Objective: to evaluate initial effectiveness of swallowing rehabilitaton for patients with post-acute stroke dysphagia in Neurology Center of Bachmai Hospital. Methods: a quasi-experiment design were conducted in 96 acute onset dysphagia after stroke patients in Bachmai Hospital from January to June 2021. The Gugging Swallowing Screen was used to assess the dysphagia level of participants. Results: The mean ages of participants was 61 to 70 years old group. After attending the swallowing rehabilitation program, participants reported a significantly improvement in swallowing function (GUSS mean score increased from $11,09 \pm 3,37$ to $14,31 \pm 1,87, p<0,0001)$. Conclusion: The swallowing rehabilitation program showed promissing results in improving swallowing function in patients with dysphagia after acute stroke. 
Keyword: Stroke, hypertension, dysphagia, swallowing rehabilitation

\section{I. ĐẶT VẤN ĐỀ}

Đột quy. não (ĐQN) là một bệnh rất nghiêm trọng và thường để lại hậu quả nặng nề cho bản thân người bệnh, gia đình và toàn xã hội nếu không được chăm sóc và điều trị kịp thời. Tỷ lệ tử vong do đột quị não đứng hàng thứ ba sau bệnh ung thư và tim mạch, còn tỷ lệ tàn phế do đột quị não đứng hàng đâu trong các bệnh lý về thần kinh[2] Rối loạn nuốt sau ĐQN xảy ra ở 23$65 \%$ người bệnh, trong số này, có 37\% phát triển thành viếm phổi hít và gây ra những hậu quả nghiêm trọng[6] Các hậu quả khác của rối loạn nuốt là tình trạng suy dinh dưỡng, mất nước, kéo dài thời gian nằm viện và tiên lượng xấu. Điều này đặt ra nhu câu cân thiết phải phục hồi chức năng sớm với rối loạn nuốt cho người bệnh để đề phòng các biến chứng. Quan điểm trước đây cho rằng $\mathrm{PHCN}$ nên được thực hiện sau khi có di chứng, tuy nhiên hiện nay, PHCN từ giai đoạn cấp có tác động đến tính mềm dẻo của não và có thể thúc đâyy cải thiện tình trạng bệnh nhằm hạn chế tối đa các thương tật thứ cấp có thể xảy ra [3]. Xuất phát từ thực tế trên chúng tôi tiến hành nghiên cứu đề tài này với hai mục tiêu:

1. Mô tả tình trạng rối loạn nuốt của người bệnh nhồi máu não

2. Đánh giá kết quả phục hồi chức năng sớm với rôi loạn nuôt ở người bệnh nhồi máu não câp điều trị tại Trung Tâm Thần Kinh Bệnh Viện Bạch Mai. II. ĐỐl TƯỢNG VÀ PHƯƠNG PHÁP NGHIÊN CỨU

Gồm 96 người bênh đột quy não cấp (theo tiêu chuẩn của WHO) có rối loạn nuốt được điều trị tại Trung tâm Thân Kinh - BV Bạch Mai

- Tiêu chuẩn lựa chọn: người bệnh được chẩn đoán nhồi máu não lần đâu có rối loạn nuốt được đánh giá qua thang điểm GUSS, tỉnh táo và hợp tác với nhân viên y tế

\section{- Tiêu chuẩn loai trừ}

- Người bệnh nhồi máu não (NMN) có rối loạn ý thức hôn mê hoặc tỉnh táo nhưng không hợp tác với nhân viên y tế.

- Người bệnh NMN tái phát.

- Người bệnh NMN có tổn thương não khác kèm theo: chảy máu màng não, u não, di căn não...

*Thời gian và địa điểm nghiên cứu

- Thời gian nghiên cứu: từ tháng 1 đến tháng 6 năm 2021.

- Trung tâm Thân Kinh - BV Bạch Mai.

*Phương pháp nghiên cứu

- Thiết kế nghiên cứu: Phương pháp giả thực nghiệm không có nhóm chứng (quasi-experiment)
- Phương pháp chọn mẫu: chọn mẫu thuận tiện cho mục tiêu nghiển cứu

\section{KẾT QUẢ NGHIÊN CỨU}

Một số đặc điểm lâm sàng của người bệnh nhồi máu não cấp có rối loạn nuốt

Bảng 1: Tỷ lệ phân bồ theo nhóm tuôii.

\begin{tabular}{|c|c|c|}
\hline Nhóm tuối & $\mathbf{N}=\mathbf{9 6}$ & Tỷ lệ \% \\
\hline$<\mathbf{5 0}$ & 12 & 12,5 \\
\hline $\mathbf{5 0 - 6 0}$ & 26 & 27,1 \\
\hline $\mathbf{6 1 - 7 0}$ & 33 & 34,4 \\
\hline $\mathbf{7 1 - 8 0}$ & 21 & 21,9 \\
\hline $\mathbf{8 8 0}$ & 4 & 4,1 \\
\hline \multicolumn{2}{|c|}{ Tuối trung bình } & $62,22 \pm 11,77$ \\
(Mean \pm SD; min - max) & $(23-87)$ \\
\hline
\end{tabular}

Nhận xét: Phần lớn người bệnh ở độ tuổi từ 61-70 tuổi (33 người, chiếm 34,4\%).Tuổi trung bình của đối tượng tham gia nghiên cứu là 62,22 \pm 11,77 (người nhỏ tuổi nhất 23 tuổi và lớn tuổi nhất là 87)

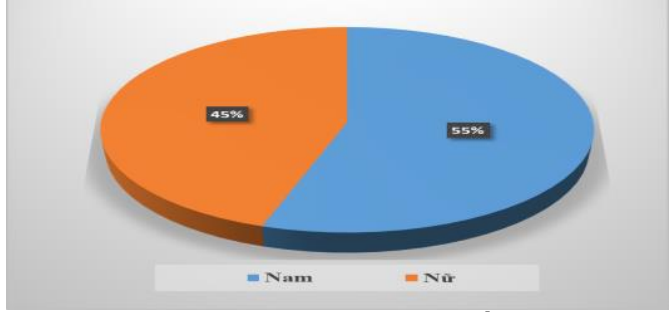

Biểu đồ 1: Phân bốtỷ lệ mắc theo giới

Nhận xét: Trong nghiên cứu này, số người bệnh là nam chiếm tỉ lệ cao hơn so với nữ (55\%, tương đương 53 người)

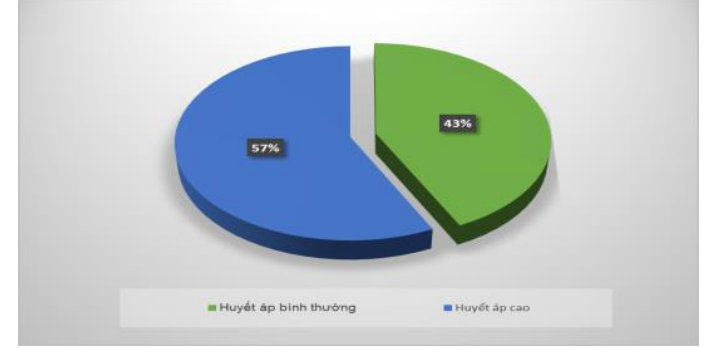

Biểu đồ 2. Chỉ số huyêt áp

Nhận xét: Trước can thiệp, đa số người bệnh có chỉ số huyết áp cao (57\%)

Đánh giá hiệu quả sau can thiệp bằng bài tập nuốt

Bảng 2. Tỉ lệ người bệnh có các triệu chứng của rôi loạn nuốt trước và sau can thiệp

\begin{tabular}{|c|c|c|c|}
\hline $\begin{array}{c}\text { Triêuu } \\
\text { chứng }\end{array}$ & $\begin{array}{c}\text { Trước can } \\
\text { thiệp } \\
(\mathbf{n = 9 6 )}\end{array}$ & $\begin{array}{c}\text { Sau khi can } \\
\text { thiệp } \\
\text { (n=96) }\end{array}$ & $\mathbf{p}$ \\
\hline Nuốt khó & $96(100 \%)$ & $88(91,7 \%)$ & 0,008 \\
\hline $\begin{array}{c}\text { Ho/sặc khi } \\
\text { nuốt }\end{array}$ & $37(38,5 \%)$ & $7(7,3 \%)$ & $<$ \\
\hline
\end{tabular}




\begin{tabular}{|c|c|c|c|}
\hline Chảy nước dãi & $27(28,1 \%)$ & $0(0 \%)$ & $<0,001$ \\
\hline Hạn chế nhai & $93(96,9 \%)$ & $41(42,7 \%)$ & $<0,001$ \\
\hline $\begin{array}{c}\text { Tồn đọng } \\
\text { thức ăn trong } \\
\text { khoang miệng }\end{array}$ & $94(97,9 \%)$ & $45(46,9 \%)$ & $\begin{array}{c}< \\
0,001\end{array}$ \\
\hline $\begin{array}{c}\text { Thay đối } \\
\text { giọng sau khi } \\
\text { nuốt }\end{array}$ & $37(38,5 \%)$ & $1(1 \%)$ & $\begin{array}{c}< \\
0,001\end{array}$ \\
\hline
\end{tabular}

Nhân xét: Tỉ lệ người bệnh có triệu chứng nuốt khó, ho khi nuốt, chảy nước dãi, hạn chế nhai, tồn đọng thức ăn trong khoang miệng và thay đổi giọng nói sau khi nuốt ở người bệnh sau can thiệp đều giảm so với trước can thiệp $(p<0,05)$.

\begin{tabular}{|c|c|c|c|}
\hline $\begin{array}{l}\text { Khả năng } \\
\text { nuốt theo } \\
\text { GUSS }\end{array}$ & $\begin{array}{c}\text { Trước can } \\
\text { thiệp } \\
(n=96)\end{array}$ & $\begin{array}{c}\text { Sau khi } \\
\text { can thiệp } \\
(\mathrm{n}=96)\end{array}$ & $\mathbf{p}$ \\
\hline lặng: 0-9 điểm & $39(40,6 \%)$ & $13(13,5 \%)$ & $\begin{array}{c}< \\
0,001\end{array}$ \\
\hline $\begin{array}{l}\text { Truns } \\
10-12\end{array}$ & $54(56,2 \%)$ & $78(81,3 \%)$ & $\begin{array}{c}< \\
0,001\end{array}$ \\
\hline hẹ: 15-19 điểm & \%) & $5(5,2 \%)$ & 0,36 \\
\hline $\begin{array}{l}\text { Điểm GUSS } \\
\text { (Mean } \pm \text { SD } \\
\text { Min - max) }\end{array}$ & $\begin{array}{c}11,09 \pm 3,37 \\
(5-15)\end{array}$ & $\begin{array}{l}14,31 \\
\pm 1,87 \\
(9-19)\end{array}$ & $\begin{array}{r}< \\
0,00\end{array}$ \\
\hline
\end{tabular}

Nhân xét: Mức độ khó nuốt theo thang điểm GUSS của người bệnh được cải thiện rõ rệt sau can thiệp. Tỉ lệ người bệnh khó nuốt mức độ nặng giảm từ $40,6 \%$ xuống còn $13,5 \%$ sau can thiệp $(p<0,001)$; mức độ trung bình tăng từ $56,2 \%$ đến $81,3 \%(p<0,01)$.

Điểm GUSS trung bình của người bệnh trước can thiệp là $11,09 \pm 3,37$, sau can thiệp tăng một cách có ý nghĩa lên $14,31 \pm 1,87$ $[\mathrm{t}(95)=8,91, \mathrm{p}<0,0001]$

Bảng 4. Mức độ rôi loạn nuốt của người bệnh trước và sau can thiệp

\begin{tabular}{|c|c|c|c|}
\hline $\begin{array}{c}\text { Rối loạn } \\
\text { nuốt }\end{array}$ & $\begin{array}{c}\text { Trước can } \\
\text { thiệp (\%) }\end{array}$ & $\begin{array}{c}\text { Sau khi } \\
\text { can thiệp } \\
(\%)\end{array}$ & P \\
\hline $\begin{array}{c}\text { Không RL } \\
\text { nuốt }\end{array}$ & $0(0 \%)$ & $5(5,2 \%)$ & \\
\hline Nhe & $3(3,1 \%)$ & $78(81,3 \%)$ & $<0,01$ \\
\hline Trung bình & $53(55,2 \%)$ & $12(12,5 \%)$ & $<0,01$ \\
\hline Nặng & $40(41,7 \%)$ & $1(1 \%)$ & $<0,01$ \\
\hline
\end{tabular}

Nhận xét: Nhìn chung, mức độ rối loạn nuốt của người bệnh được cải thiện một cách rõ rệt sau can thiệp. Tî lệ người bệnh rối loạn nuốt mức độ nhe tăng từ 3,1\% trước can thiệp lên 81,3\% sau can thiệp. Với rối loạn nuốt ở mức độ trung bình, trước can thiệp có 55,2\%, giảm xuống còn $12,5 \%$ sau can thiệp. Tương tự như vậy, trước can thiệp có $41,7 \%$ người bệnh có rối loạn nuốt mức độ nặng, sau can thiệp tỉ lệ này giảm xuống còn $1 \%$ với $(\mathrm{p}<0,001)$

Bảng 5. Khả năng nuốt được các dạng thức ăn của người bệnh trước và sau can thiệp

\begin{tabular}{|c|c|c|c|}
\hline $\begin{array}{c}\text { Danng } \\
\text { thức ăn }\end{array}$ & $\begin{array}{c}\text { Trước can } \\
\text { thiệp } \\
(\mathbf{n = 9 6 )}\end{array}$ & $\begin{array}{c}\text { Sau khi can } \\
\text { thiệp } \\
(\mathbf{n = 9 6 )}\end{array}$ & $\mathbf{P}$ \\
\hline Lỏng & $36(37,5 \%)$ & $3(3,1 \%)$ & $<0,001$ \\
\hline Đặc & $56(58,3 \%)$ & $9(9,4 \%)$ & $<0,001$ \\
\hline Rắn & $4(4,2 \%)$ & $79(82.3 \%)$ & $<0,001$ \\
\hline $\begin{array}{c}\text { Không có rối } \\
\text { loạn nuốt }\end{array}$ & $4(4,2 \%)$ & $5(5,2 \%)$ & 0,63 \\
\hline
\end{tabular}

Nhân xét: Khả năng nuốt các dang thức ăn của người bệnh sau can thiệp có sự cải thiện rõ rệt. Người bệnh có xu hướng nuốt được các thức ăn dạng đặc dần. Trước can thiệp có đến 37,5\% người bệnh chỉ nuốt được thức ăn lỏng, sau can thiệp tỉ lệ này giảm xuống còn $3,1 \%(p<0,001)$. Với dạng thức ăn đặc, trước can thiệp có $58,3 \%$ người bệnh ăn được loại này, sau can thiệp giảm xuống còn $9.4 \%(p<0,001)$. Số người bệnh nuốt được các loại thức ăn dạng rắn tăng lên đáng kể sau can thiệp (từ 4,2\% lên 82,3\%, $\mathrm{p}<0,001$ ).

\section{BÀN LUÂN}

\section{Đặc điểm chung vê đôi tượng nghiên cứu}

Đặc điểm về tuổi: Tuổi trung bình của đối tượng tham gia nghiên cứu là $62,22 \pm 11,77$ (người nhỏ tuổi nhất 23 tuổi và lớn tuổi nhất là 87). Phần lớn người bệnh ở độ tuổi từ 61-70 tuổi (33 người, chiếm 34,4\%). Số người bệnh có tuổi trên 80 chiếm tỉ lệ thấp nhất $(4,1 \%$ với 4 người). Sự phân bố về tuổi của người bệnh trong nghiên cứu của chúng tôi tương đương với nghiên cứu Nguyễn Thế Dũng (2009).[1]

Đặc điểm về giới: Kết quả phân bố theo giới thể hiện ở biểu đồ 1 . Số người bệnh nam là $55 \%$, tương đương 53 người bệnh. Số người bệnh nữ 45\%, tương đương 43 người bênh. Tỷ lệ Nam/Nữ là 1,23. Theo Nguyễn Thế Dũ̃ng (2009) là 1,5 . Nghiên cứu của Trapl là 1,1 . Trong hầu hết các nghiên cứu thì tỷ lệ nam đều cao hơn nữ. Điều này có thể do nam có nhiều yếu tố nguy cơ hơn nữ như uống rượu, bia, hút thuốc lá, thói quen ăn uống và sinh hoạt không điều độ $[1,7]$

Chỉ số huyết áp: Với số liệu trong nghiên cứu của chúng tôi (Biểu đồ 2), đa số người bệnh có chỉ số huyết áp cao (55/96 người bệnh, chiếm tỷ lệ $57 \%$ ). Kết quả này cũng phù hợp với nghiên cứu của Nguyễn Thế Dũng và Trần Văn Tuấn và Nguyễn Thị mai là $64,3 \%$. Và $65,6 \%[1,4]$

Hiệu quả của các bài tập nuốt ở bệnh 


\section{nhân NMN cấp có RLN}

Các triệu chứng: nuốt khó, ho khi nuốt, chảy nước dãi, hạn chế nhai, tồn đọng thức ăn trong khoang miệng và thay đổi giọng nói sau khi nuốt ở người bệnh sau can thiệp đều giảm so với trước can thiệp. Điều này cho thấy sau khi bị đột quỵ nếu như người bệnh được đánh giá, phân loại và có kế hoạch chăm sóc và tập luyện $\mathrm{PHCN}$ sớm phù hợp kịp thời thì khả năng hồi phúc sẽ tốt hơn. Điều này cũng đồng thuận với nhận định của các tác giả khác[5]

Điểm GUSS trung bình của người bênh trước can thiệp là $11,09 \pm 3,37$, sau can thiệp tăng một cách có ý nghĩa lên $14,31 \pm 1,87[\mathrm{t}(95)=$ $8,91, p<0,0001]$. Điều này cho thấy sau khi bị ĐQN có RLN nếu như người bênh được phục hồi chức năng nuốt sớm thì khả năng hồi phục sẽ tốt hơn, kết quả này cũng phù hợp với nhận định của các tác giả khác [3].

Bảng 4 và 5 cho thấy mức độ rối loạn nuốt trước và sau can thiệp được cải thiện rõ rệt, cùng với khả năng nuốt các dạng thức ăn cũng được cải thiện tốt đặc biệt số người bệnh nuốt được các loại thức ăn dạng rắn tăng lên đáng kể sau can thiệp (từ $4,2 \%$ lên $82,3 \%, p<0,001$ ). Như vậy khi can thiệp bài tập nuốt sớm cho người bệnh NMN cấp có rối loạn nuốt đem lại hiệu quả cao hơn khi so với trước can thiệp. Kểt quả này có thể mở đầu cho việc áp dụng các bài tập nuốt sớm cho người bệnh nhằm cải thiện triệu chứng và phục hồi tốt cho người bệnh đột quỵ não có rối loạn nuốt.[4]

\section{KẾT LUÂN}

- Vây PHCN sớm cho người bênh đôt quy não cấp có rối loạn nuốt giúp cải thiện tình trạng nuốt của người bệnh. Kết quả có ý nghĩa thống kê.

- Đánh giá sau can thiệp các triệu chứng được cải thiện nhiều hơn so vói trước can thiệp

Khuyến nghị. Rối loạn nuốt là khiếm khuyết thần kinh thường gặp sau đột quy, làm tăng nguy cơ viêm phổi, tử vong và kéo dài thời gian nằm viên. Phục hồi chức năng rối loạn nuốt sớm sau đột quỵ nên phối hợp đa chuyên ngành bao gồm điều dưỡng và chuyên viên âm ngữ trị liệu.

\section{TÀI LIÊU THAM KHẢO}

1. Nguyễn Thế Dũng; (2009), Nghiên cứu đánh giá tình trạng rối loạn nuốt ơ bênh nhân tai biến mạch máu não chưa đặt nội khí quản điều trị tại bệnh viện Bạch Mai, Luận văn Thạc sỹ Y học, Đại học $Y$ hà Nội.

2. Nguyến Minh Hiên; (2013), Đột quỵ não, Nhà xuất bản $Y$ học.

3. Lương Tuấn Khanh; (2020), Chăm sóc và phục hồi chức năng sớm sau đột quy, Dự án hỗ trợ cải thiện chất lượng chăm sóc đột quỵ- Bệnh viên Bach Mai.

4. Trần Văn Tuấn và Lê Thị Mai; "Nghiên cứu đặc điểm lám sàng và đánh giá hiệu quả của các bài tập nuốt trên bệnh nhân có rối loạn dinh dưỡng sau đô̂t quy", KHOA HOCC \& CÔNG NGHÊ. 89(01/2), tr. 59-63.

5. B. H. Dobkin (2005), "Clinical practice. Rehabilitation after stroke", N Engl J Med. 352(16), tr. 1677-84.

6. L. Perry và C. P. Love (2001), "Screening for dysphagia and aspiration in acute stroke: a systematic review", Dysphagia. 16(1), tr. 7-18.

7. M. Trapl và các cộng sự. (2007), "Dysphagia bedside screening for acute-stroke patients: the Gugging Swallowing Screen", Stroke. 38(11), tr. 2948-52.

\section{ĐÁNH GIÁ THỰC TRẠNG BỀNH TÂT TRẺ EM XÃ THẢI GIÀNG PHỐ, HUYÊ̂N BẮC HẦ, TỈNH LÀO CAI NĂM 2019}

\section{TÓM TẮT}

Mục tiêu: Đánh giá thực trạng bệnh tật trẻ em tại xã Thải Giàng Phố, huyện Bắc Hà, tỉnh Lào Cai năm 2019. Phương pháp và đối tượng: Nghiên cứu mô tả cắt ngang có phân tích trên các trẻ từ 0-14 tuổi tại trường mẫu giáo, tiểu học và trung học tại xa Thải Giàng Phố, huyện Bắc Hà, Lào cai. Kết quả: Nghiên

*Trung tâm Chăm sóc sức khỏe ban đầu Nhi khoa Bệnh viện Nhi Trung ương

Chịu trách nhiệm chính: Phạm Ngọc Toàn

Email: ngoctoancard@yahoo.com

Ngày nhận bài: 17.6.2021

Ngày phản biên khoa hoc: 12.8.2021

Ngày duyệt bài: 23.8.2021
Phạm Ngoc Toàn*

cứu trên 870 trẻ, trong đó $65,4 \%$, trẻ tiêm vắc xin đây đủ, đẻ đủ tháng $74,7 \%, 72,8 \%$ đẻ đủ cân trên $2500 \mathrm{~g}$, $4,6 \%$ được sinh bằng biên pháp mổ. Bất thường khi đẻ chủ yểu là ngạt $(3,1 \%)$, võ ối trước sinh $(2,0 \%)$. Các bênh về Răng-Hàm-Măt (RHM) và dinh dưỡng cao hơn hẳn so với các nhóm bệnh khác $(32,1 \%$ và $31,9 \%)$, suy dinh dưỡng thể thấp còi $66,7 \%$. bệnh về Tai-Mũi-Họng (TMH) và da liễu $(18,2 \%$ và $12,4 \%)$. Các bênh về mắt, hô hấp, tuần hoàn, tiêu hóa, thần kinh chiếm dưới $3 \%$. Những trẻ được tiêm chủng đây đủ có nguy cơ bị các bệnh về TMH chỉ bằng 0,54 so với các trẻ không được tiêm chủng đầy đủ. Kết luận: Tỉ lệ trẻ được tiêm chủng đầy đủ là $65,4 \%$. Trẻ chủ yếu mắc các bệnh về Răng-Hàm-Mặt $(32,1 \%)$, dinh dưỡng $(31,9 \%)$, Tai-Mũi-Họng $(18,2 \%)$ và da liễu (12,4\%). 